\title{
SUSTAINABLE CONSUMPTION AND PRODUCTION
}

\author{
Teaching Assistant PhD Student Florin Frant, "Eftimie Murgu” University \\ of Reşița,e-mail: florin_frant@yahoo.com \\ Associate Professor PhD Mirela Minică, "Eftimie Murgu" University \\ of Reşița, e-mail: minica_mirela@yahoo.com
}

\begin{abstract}
This study (National Strategy) is built on the premise that accelerated development in the medium and long run in its three essential components (economic, social and environmental) is not just one of the possible options, but an essential precondition for gradually closing the gap which still separates Romania, in terms of quality of life, from the EU average level within the shortest possible time and for ensuring real cohesion both nationally and in the broader EU framework.

The economic developments in Romania over the past 7 years (2001-2007), with an annual growth rate of the gross domestic product of more than 6\% compared to the EU average of under $2 \%$, demonstrate that it is possible to attain this objective.
\end{abstract}

Key words: sustainable, development, economic

JEL Codes: O11, O18, O21, O41.

\section{Introduction}

The economic developments in Romania over the past 7 years (2001-2007), with an annual growth rate of the gross domestic product of more than $6 \%$ compared to the EU average of under $2 \%$, demonstrate that it is possible to attain this objective. The fact that Romania joined the Single Market of the European Union, the improved business environment and ability to face competitive pressures, the consolidation of the private sector and the rising rate and quality of investment are encouraging factors that support the continuation of this process.

Continued growth of the GDP at average annual rates of 5.6-5.8\% between 2008 and 2013, 4.8-5\% between 2014 and 2020 and 3.8-4.2\% between 2021 and 2030 is a realistic target. The figures are close to the estimated potential GDP levels for each period and compatible with the convergence criteria that Romania needs to meet in order to adopt the common European currency.

At a time when the free movement of goods and services and the effects of globalization become more widespread, eco-efficiency and competitiveness will be key factors of sustainable economic growth. The continued performance of the Romanian economy in the medium and longterm requires, therefore, effective economic policy instruments that should make it possible better to manage and turn to account the existing potential in certain key areas that are essential for sustainable development in a competitive environment.

\section{To promote sustainable consumption and production patterns.}

A realistic approach to this thematic area requires the evaluation of the production and consumption pattern that has characterized recent developments in the Romanian economy, with a view to finding solutions to reduce the consumption of material resources per unit of gross value added and to decouple the dynamic of the gross domestic product (GDP) from that of the aggregated consumption of material and energy resources and its negative impact on the environment. 
With reference to the figures for the year $2000(=100 \%)$, the production of goods and services grew by $62.3 \%$ between 2001 and 2007, while the gross value added increased by only $52,1 \%$ as a result of a $71.4 \%$ increase of intermediary consumption (the value of goods and services purchased and consumed, excluding fixed assets). The corroboration of these data indicates that, during that period of time, the dynamic of value added was inferior to that of the output, despite favorable trends in labor productivity. Actually, production growth was achieved by resorting to higher resource consumption. The ratio between the GDP dynamic and the growth of intermediary consumption was a negative one throughout those years and even tended to deteriorate $(95.9 \%$ in $2001,99.4 \%$ in $2002,96.5 \%$ in $2003,99.3 \%$ in $2004,99.5 \%$ in $2005,98.2 \%$ in 2006 and $99.4 \%$ in 2007).

It results from the above-quoted figures that the Romanian development pattern of the past five years (which also applies to previous periods) was based on a model that runs against the principles of sustainable development that are being promoted by the European Union of which Romania is now a part. The continuation of this trend threatens the long-term sustainability of economic growth due to an excessive and irrational use of resources, with negative consequences on the state of the natural capital and on social and human development in a competitive environment.

Structural imbalances persist in Romania with regard to food consumption, along with quality deficiencies in the production and sale of foodstuffs. At the same time, the farming sector fails to ensure the access of the entire population to rational nutrition, despite the availability of favorable natural conditions enabling it to cover at least the necessary requirements for domestic consumption. Prices for some foodstuffs remain inaccessible to vulnerable population groups. Farm production for own consumption is still high, particularly in rural areas, while basic foodstuffs have to be imported to supply the urban areas.

The situation needs to be addressed through adequate policies and instruments, in accordance with market principles and relevant EU regulations designed to change the consumption-oriented mentality and the propensity for shot-term profit maximization. To this end, an in-depth analysis of the factors behind the current situation needs to be completed in the near future in order to establish the suitable economic policies toward a significant growth of resource productivity.

Horizon 2013. National Objective: To achieve eco-efficient management of resource consumption and to maximize resource productivity by promoting a pattern of consumption and production that makes sustainable economic growth possible and brings Romania gradually closer to the average performance of the other EU countries.

Structural adjustment of the economy is the main way of enhancing resource productivity by increasing the relative share of the products, processes and activities that use a smaller amount of energy and material resources to achieve higher value added.

In that respect, the most resource-efficient segment of the Romanian economy is the service sector. With reference to the year 2005, total resource productivity in the service sector has been substantially higher than in the manufacturing industries or construction. Although the structure and quality of the services in Romania is not yet adapted to the demands of modern economy, this sector is the only one where the value added has exceeded resource consumption (by 39.3\%).

The potential for the development and upgrading of the service sector, with its favorable financial, economic, social and environmental effects, is illustrated by a comparison to the situation in other EU Member States. The contribution of the Romanian service sector to the gross domestic product is approximately 50\%, way behind the performance of Bulgaria's (59\%), Poland and Hungary (61-65\%), Slovakia, Sweden, Austria, Germany (67-69\%), Italy, Portugal, the United Kingdom, Greece, The Netherlands (71-74\%) and France (77\%). The EU average is around $70 \%$ of GDP. For example, the per capita revenue from tourism in Romania, in 2006, was 3 to 8 times lower then in Poland, Bulgaria, Hungary and the Czech Republic. 
Moreover, in the same year 2006, Romanian tourism showed a deficit (ratio between income and spending) of Euro 1 million, while Bulgaria produced a surplus of Euro 891 million.

The development, specialization and improved quality of services do not represent ultimate goals by themselves: they are only a specific instrument used by modern economies to increase efficiency and competitiveness in all the other sectors of the economy and society. The contribution of research, development and innovation activities, information technologies, transport and communications, continuous training and professional improvement of the labor force, expansion of financial intermediation and other services does not inhibit the development of directly productive sectors (manufacturing industries, construction, agriculture, forestry, fishing and aquaculture, etc.) but rather enhances their potential for modernization and improved resource efficiency.

The period between 2008 and 2013 will see more incentives for the development of certain categories of services that can have a major positive impact in terms of increased resource productivity and eco-efficiency, with a multiplier effect in other sectors of the economy: development of technologies that help reduce energy and physical resource consumption for products and processes, consultancy and expertise for the eco-efficient utilization of the funding available for upgrading infrastructure and production processes, marketing operations to increase the efficiency of sales and purchases, including green public procurement, and optimal placement of Romanian goods and services in the most favorable niche markets.

Further measures will encourage a significant improvement of the quality of services supplied on the EU Single Market as a persuasive argument for reinforcing the perception of Romania's competitiveness. The development of services in rural areas (commercial and financial services, consultancy for farming and public works, transport and agro-tourism, human health and veterinary services, etc.) will make it possible to tap additional sources for GDP growth by providing alternative employment opportunities to people currently engaged in farming (who represent $30.5 \%$ of the active population, but contribute less then $9 \%$ to the GDP). This will also enhance the disposable income of rural residents and may help reduce the share of subsistence agriculture in favor of commercially viable farming.

Effective resource use depends greatly on the developments in intra-sector structures. Industrial activities, the sector having the highest consumption of resources, have undergone major structural adjustments, particularly between 2000 and 2007.

In the mining sector, excavation of metal-bearing ores was abandoned in sites that had low useful content and high operation costs, which no longer justified the allocation of state subsidies. The subsidies for brown coal and uranium ore mining have been gradually phased out and will be completely discontinued by 2010 .

In the electric power industry, production increase (13.9\%) was below overall industrial output growth $(41.3 \%)$ as a result of decreasing energy intensity.

However, resource productivity went down because of increased intermediary consumption $(15.6 \%)$ and lower value added. The growing share of hydro and nuclear power generation, technological upgrading of thermoelectric plants and higher input from renewable sources that are foreseen for the following period will reverse this trend.

The manufacturing industries tended to show a higher dynamic of growth $(51.1 \%$ in 2007 relative to 2000) compared to mining (3.1\%). Resource productivity improved thanks to increased production of road vehicles $(188.8 \%)$, electrical machinery and equipment $(59.6 \%)$, furniture $(77 \%)$ and food industry (77\%), where the growth of gross value added exceeded resource consumption. It is estimated that the positive trends in these sub-sectors will continue in the following years.

Between 2008 and 2013 and thereafter, the industrial policy will pursue both the strategic objectives and specific targets of the national economy and the EU trends, in line with the tenets of sustainable development. The main targets for the development of various industrial sectors in the medium term are: 
- To maintain and develop an attractive business environment that can enhance investment flows, stimulate technological upgrading and encourage continued renewal of processes and products;

- To support research, development and innovation in close connection with the actual needs of industry and market demand in order to obtain competitive advantages and to reduce the technology and productivity gaps relative to the more advanced EU countries;

- To promote the use of information and communication technologies (ICT) at all stages, from design to production to marketing, including business administration;

- To develop competitive market practices under the rules of the EU Single Market and to avoid the emergence of cartels or monopolistic attempts at exclusive control of the market;

- To refine sectorial assistance and upgrade the role of public authorities in the preparation and implementation of industrial policies and the administration of restructuring and development processes in keeping with EU practice;

- To encourage direct foreign investments as sources of capital, know-how, technology and managerial skills;

- To render continued support for the development of small and medium enterprises (SME) in manufacturing industries in order to enable them to address market demand with highquality products at lower costs.

Preliminary estimations indicate that the application of adequate economic policy instruments could result in a 3-4\% annual increase in physical and energy resource productivity during the period 2008-2013 through:

- Macroeconomic structural adjustment (raising the service sector contribution to the GDP from 48.8 in 2005 to about $55 \%$ in $2013,60-65 \%$ in 2020 and $70 \%$ in 2030) and intrasectored structural adjustment (lower share of energy and material intensive sub-sectors in industry);

- Reduction by a minimum of $1.2-1.5 \%$ per year of the specific consumption rates for materials and energy and production losses in the processing industries, power generation, residential sector, transport and construction following a significant increase in investment for technological renewal and infrastructure upgrading, and also as a result of better management of technology and energy;

- A 2-3\% annual increase of the share of products having high value added and relying on medium-grade and high technology, and also of the share of services in the structure of exports;

- Significant improvement in the technological content and the quality of products and services leading to better performance on the market and higher value added in relation to the cost of resources actually used;

- Enhanced commercial management, better procedures for the acquisition of raw materials (particularly energy resources), materials, components and services, and improved terms of sale of products and services on the most favorable niche markets in relation to the international fluctuation of prices.

By meeting these perfectly feasible objectives, it is estimated that over $60 \%$ of the economic growth can be accomplished without additional consumption of material and energy resources.

Increased resource productivity will also lead to a lower depletion rate of the main categories of primary resources and will help reduce costs, improve competitiveness and achieve sustainable economic growth.

In the field of agriculture and food production there will be a greater emphasis on food security and safety. Agriculture will continue to have a key role in providing income to a significant segment of the active population in the form of self-employment, while the diversification of activities in rural areas will demand complex interventions over time. The effort to promote a 
sustainable consumption and production pattern along with the protection of ecosystems and decupling economic growth from environmental degradation will ensure the sustainability of food production, the reduction and elimination of imbalances on the markets for farm produce that are caused by the current misuse of natural resources and will better turn to account the comparative advantages of Romanian agriculture. To this end, rational and coherent policies will have to be implemented in order to achieve the sustainable development of agriculture and processing of farm products, and to encourage quantitative growth and improved quality of food production and consumption at sustainable levels.

The implementation of the European Action Plan for Sustainable Consumption and Production with an aim to reducing the negative impact of human activities on the environment during the 2008-2013 period will make it necessary to engage in permanent and systematic dialogue with the business community and social partners with a view to setting agreed targets for the ecological and social efficiency of the main products and processes.

The implementation of the measures included in the ETAP Action Plan to support the introduction of ecological technologies and to encourage eco-innovation by applying the national road map will bolster the demand for, and the production of specialized equipment and procedures in all sectors of the economy. The correlation of the targets set in the sectored operational programmers, particularly the National Strategy for scientific research and technological development, with those of regional development will encourage the dissemination of innovations that bring social and environmental benefits and will help the spread of technologies designed to improve environmental conditions and to promote the rational utilization of non-renewable natural resources and the sustainable use of renewable resources.

Research, development and innovation activities as well as those aimed at promoting ecoefficient technologies will be focused, as a matter of priority, on those sectors where the expected effects are the most significant in terms of ecological progress and competitiveness (organic foodstuffs, water-management technology, energy efficiency, urban transport, industrial processes having a major environmental impact, construction business, selective waste collection, recycling and disposal, befouls, etc.).

A system of green public procurement will be phased in with an aim to come close to fulfilling, by 2013, the EU objective to reach, by 2020, the average level attained by the best performing Member States in 2006. For this purpose, all public institutions that have such responsibilities will prepare relevant terms of reference spelling out procurement requirements by groups of products or services and providing also updated information on the best practice of green public procurement available in the other EU Member States. It is also advisable to consider the possibility of working out, in collaboration with the business associations, a set of voluntarily undertaken rules and objectives aimed at introducing environmental criteria in procurement activities of private sector operators.

Product labeling will be expanded gradually, in accordance with EU norms, to reflect the environmental performance of goods on sale. Coherent information campaigns will be organized to inform the consumers (with the assistance of retail businesses, market regulators and organizations of the civil society) and to promote the eco-efficient products and services, including those resulting from organic farming.

In order to ensure sustainable production and consumption in conformity with the EU objectives, the following specific regulations will be enacted:

- The obligation to include in the annual balance sheets and in the income and expenditure budgets of enterprises an indicator on «resource productivity» to be measured by the ratio between gross value added and the cost of material and intermediary consumption. The introduction of this indicator makes it possible to develop higher performance standards for managers regarding the efficiency of their purchases of goods and services, targeting both the technology side and the commercial one; to enable a more accurate evaluation by stockholders 
of the quality of management and administration in terms of sustainable development of the business; to promote effective investment policies in a medium to long-term perspective, including the introduction in daily practice of business plans and multiannual income/expenditure budgets; to explore in a systematic manner potential ways to reduce material and energy consumption and to increase productivity through technological upgrading and renewal of products in tune with market demand.

- To make it mandatory for the firms listed on the stock exchange and, starting 2010, for all businesses in industry, agriculture and transport to provide relevant information regarding the management of resources, the environmental performance of processes and activities, and the application of green labeling (the number and relative share of products carrying environmental labels).

- To improve the capacity of both public authorities and companies to implement the existing legislation on public procurement, particularly with regard to the provisions concerning the introduction of clear commitments on eco-efficiency and observance of environmental protection standards in all tender documents.

- To encourage the national, county and local public authorities to initiate, in cooperation with business associations, chambers of commerce and industry, universities and research centers, actions toward raising social awareness and corporate responsibility regarding sustainable production and consumption. This can be achieved through publicizing best practices (including online posting); direct exchanges of experience (visits and joint workshops); dissemination of opportunities in the consultancy business, project design and project management, procurement and validation of environmental protection equipment and eco-friendly technologies.

- To encourage the establishment, within the envisaged centers of excellence or as autonomous units, of specialized technological platforms and pilot projects designed to promote, as a matter of priority, eco-efficient technologies and production processes; enhanced energy efficiency; development of renewable energy resources, including bio-fuels; improved technologies for water, waste and soil management; green transport; production of ecological materials, etc. The funding for such projects can be secured from the EU Framework Programme for Research and Development (FP7), which has allocated 30\% of its total budget of Euro 32 billion for innovation and the implementation of research results.

In view of the EU recommendations, which are still under development, it is envisaged to make certain adjustments to the fiscal system entailing a partial transfer of taxation from labor to material and energy resource consumption. This can have major positive effects on sustainable development by encouraging the allocation of investments towards those sub-sectors where resource productivity is higher and inhibiting the growth of materials- and energy-intensive sectors that cannot be sustained in the long run with the currently available resources; promoting the products and services that rely on medium-grade and highly complex technologies and result in advanced processing and higher value added; increasing the share of such products and services in overall exports.

Proper resort to fiscal instruments can also result in increased savings through a reduction of the tax rate on re-invested profit with an aim to encouraging investment in enhanced product competitiveness and eco-efficiency, and also through changes in the current regulations concerning the taxation of accruing interest on bank deposits by shifting the emphasis on taxing the differential between real interest and inflation.

Horizon 2020. National Objective: To decouple economic growth from environmental degradation by reversing the ratio between resource consumption and creation of value added; to move closer to the average performance levels of the EU in terms of sustainable consumption and production.

The main target is to accelerate the overall development of the service sector and to raise its contribution to the GDP growth to about $60 \%$.

In parallel, it is envisaged to encourage the growth of those economic sectors that produce 
higher value-added with a lower consumption of materials and energy in ways which are compatible with market principles and with the EU regulations.

EU practice will be generalized with regard to the application of environmental, economic and social performance criteria in (sustainable) public procurement, the development and implementation of eco-efficient technologies and the enhancement of public awareness about the virtues and the direct benefits of sustainable production and consumption patterns.

Horizon 2030. National Objective: To come close to the average level attained at that time by the other EU Member States in terms of sustainable production and consumption.

\section{Conclusions}

Labour productivity in the entire Romanian economy (GDP per employed person) as well as at sector and enterprise levels (gross value added per employee) is still vastly inferior compared to the EU average. The relatively low level of Romanian wages, particularly at the lower end of the scale, can be explained in part by this productivity gap, which is reflected in approximately the same ratio between the quality of employment and the amount of disposable income.

The sluggish renewal of the technological base, poor quality of infrastructure, chronic under-financing, weak contribution of national research and development, substandard performance of the domestic products and services on the market, inadequate ability to adapt to globalization have been the main causes of unsatisfactory labour productivity and poor returns on the resources used. Although the rate of labour productivity growth in Romania, especially in the processing industries and construction business, has been higher than the EU average in recent years, the difference is still very high.

Since resource productivity (amounts used versus returns) and labour productivity are the main determinants of efficiency and competitiveness and, implicitly, of the sustainability of economic and social development, significant efforts will be required in terms of investment and managerial expertise to remedy the present situation and to match the current EU standards. The urgency of such measures is underscored by the unfavourable demographic developments which tend to get worse in the case of Romania.

Concurrently, it is necessary to improve the employment rate of the potentially active population; between 2002 and 2006, Romania had a rate of $57.9 \%$ compared to the EU average of $63.1 \%$ for the same period.

Focused investment in human capital development can produce an estimated employment rate for the population aged between 15 and 64 of more than $62 \%$ in 2013 and continue on an upward trend in the following period (up to $64-65 \%$ in 2020).

\section{References:}

1. Global Leaders of Tomorrow Environment Task Force et al., "2002 Environmental Sustainability Index," 2002.

2. J., E., Stiglitz, Economie, Editura economica, Bucuresti, 2005.

3. Minica Mirela, Macro-economy, fundamental elements, macro-economic unbalances, Mirton Publishing, Timisoara, 2005.

4. National Sustainable Development Strategy Romania 2013-2020-2030, Bucuresti, august 2008.

5. Pascariu, G. (coordonator), EU Cohesion Policy and Romania's Regional Economic and Social Development, Pre-Accession Impact Studies, European Institute, Bucharest, 2002

6. World Wildlife Federation International, Living Planet Report 2002, 2002. 